Media Industries $6.1(2019)$

\title{
Complex not Complicated: Gendered Media Industries in the Wake of \#MeToo
}

\author{
Skadi Loist \\ FILM UNIVERSITY BABELSBERG KONRAD WOLF \\ s.loist [AT] filmuniversitaet.de \\ Deb Verhoeven ${ }^{1}$ \\ UNIVERSITY OF ALBERTA, EDMONTON \\ deb.verhoeven [AT] ualberta.ca
}

\begin{abstract}
In the wake of \#MeToo and \#TimesUp, it has become clear that the problem of patriarchy in the screen and media industries is vast, scaled, unrelenting, and brutal in its impact. Our responses need to be equally nuanced, complex, and unyielding. This special section offers four essays that collectively represent our aim for a multifaceted, international, and intersectional set of perspectives. Read in combination they unpick industry binaries such as below-the-line versus above-the-line professions, pre- and post-industry, personal/individual versus political/structural, and North American versus (other) global industries. As such, this section is part of an urgent, on-going conversation about how to effect meaningful change in current media industries.
\end{abstract}

Keywords: Gender Equality, Gender Bias, Screen Industries, Gendered Media Production, Intersectional Feminism

This special section of Media Industries journal is a considered response to recent, widespread protest at the political organization of the media industries. Throughout screen media industries across the globe, feminists have given expression to their displeasure at the conditions of their employment, a "mass disclosing," which is often collectively summed up with the repurposed hashtag \#MeToo or \#TimesUp.

These unabated declarations of workplace harassment, discrimination and abuse at the hands of powerful male industry gatekeepers and celebrities is frequently described in media reportage as the "Weinstein effect," after the multiple accusations of sexual intimidation leveled against Hollywood producer Harvey Weinstein. Focussing attention so closely on 
individual power-brokers gives rise to hopes that the toxic masculinity described largely by women in the screen industries can be simply fixed by removing a few influential "bad apples."

Without diminishing the powerful resonance of this one Hollywood exposé, first published in the New York Times in October $2017,{ }^{2}$ there are several other ways in which this characterization of the patriarchal configuration of screen industries falls short. First, it suggests that power is individually held by a small number of executive men rather than also considering the broadly gendered social relations that define the cultures in which these industries participate. Second, it implies that these problems are new or have only been recently exacerbated. Yet since screen industry data have been recorded, the qualitative and quantitative research on discrimination against women has remained frustratingly obdurate. And finally, the global breadth of almost identical complaints has led to the belief that film industries around the globe operate in the same way to secure the domination of men thereby missing the nuance of specific national discursive and social contexts. ${ }^{3}$ What we do know about the problem of patriarchy in the screen and media industries is that although it is vast, unrelenting and brutal in its impact, it is also scaled, fungible and multilayered. Our responses need to be equally as nuanced, complex and constant.

This special section of Media Industries offers a way to consider the complexity of researching and writing about gender in the screen media sectors. The following essays collectively represent our aim for a multifaceted, international, intersectional set of perspectives. They are a way to imagine how we can move beyond pointing to the problems and inequalities in the media industries toward imagining instead which interventions will actively effect change. The essays in this special section achieve this in various ways. Read in combination, for example, they unpick industry binaries such as below-the-line versus above-the-line professions, pre- and post-industry, personal/individual versus political/structural, and North American versus (other) global industries.

Our own field of research is not immune from these kinds of conceptual abbreviations. As Miranda Banks notes about our academic contexts, discrimination is not just the object of our study but also our experience of it. In the broadest sense, these essays pose a critical question about the reflex reversion to the binaries that underlie our most fundamental conceptualizations and concerns. We must, for example-in our protests and our proposalssimultaneously address the evident discrimination against a bio-social-discursive category such as "women" and create places in our work for more tensible, intersectional and nonbinary forms of identity. As Verhoeven, Coate, and Zemaityte argue in this section there is no one-size-fits-all solution to the global scale of the problems denoted by the pithy hashtag \#MeToo. The four essays in this special section present an initial and timely response, but we do not offer them as the only conceivable responses. We present them for proposing different strategies for different aspects of gendered media production and for bringing different methodologies to the table.

The section starts off with an analysis by Miranda Banks examining how to intervene in the already present gatekeeping strategies of the film industry that operate at the training levels in universities and film schools, what she calls the "pre-industry." She starts from evidence of qualitative and quantitative studies about the inequities found within industries and preindustries, which sees women drifting to producing rather than directing and students of 
color working more often in interactive, media, animation, and documentary production than their white peers. Banks prompts us to think about ways to encourage institutions to ensure more equitable enrollment and creative development of a diverse range of young talent. She presents the game Room at the Top, designed and tested at Emerson College, as a way to simulate non-personal experiences of inequality and create a safe environment through game space to raise awareness and opportunities to discuss alternative futures.

This is followed by two different analyses of current production cultures. The first by Skadi Loist and Elizabeth Prommer offers an overview of gendered mechanisms in the German film industry based on empirical quantitative evidence. While specifically situated in the German context, this analysis can stand in for the larger European sector where several studies suggest very similar statistics and political discussions. ${ }^{4}$ Loist and Prommer note that the issue of gender inequality in screen industries is not just about individual toxic men. Instead, we see a highly gendered production culture in which a pervasive bias runs through the whole industry and creates hierarchical differences and hurdles for women seeking work in creative positions.

Priscilla Ovalle offers an actor-focused, intersectional analysis of gendered and racialized production cultures in her study of celebrity hair stylist Kim Kimble. By focusing on the development of Kim Kimble's exceptional career, Ovalle uncovers how this has simultaneously been highly gendered and racialized. She ties her analysis to a matrilinear, Black American history of the craft explaining how Kim Kimble built on the knowledge of her mother and grandmother, and now helps her sisters within a profession when most hair styling dynasties tied to Hollywood have been run by white men.

The section closes with an empirical analysis by Deb Verhoeven, Bronwyn Cote, and Vejune Zemaityte written from the perspective that data can do more than just describe and that it also offers insights for political intervention. Their work examines the way that global feature film distribution patterns reveal gendered gatekeeping and fundamentally impact the visibility of women's work. Their research reveals the extraordinary amplification of women's effort if men collaborate rather than compete with them.

Given patriarchy's notable capacity for perseverance, we look forward to future issues of this journal that examine and evaluate in detail emerging standards of accountability in the media industries. The BFI Diversity standards, for example, designed to intervene in all levels of the screen industry from story development and representation, to career development and sustainability, as well as exhibition and audience access; the $50 / 50$ by 2020 pledges signed by all major film festivals; of inclusion riders; the Women in Film's ReFrame Gender Parity stamp; and of the long list of national and regional funding schemes, such as Screen Australia's "Gender Matters," the Eurimage Gender Equality Strategy, or the Canadian initiative 2xMore. Now, more than ever, we need persuasive, evidence-based analysis of the political responses to \#MeToo to ensure these actions are more than lip service and will lead to effective change.

${ }^{1}$ Skadi Loist is Visiting Professor for Production Cultures in Audiovisual Media Industries at the Film University Babelsberg KONRAD WOLF in Potsdam, Germany, and leads the research project "Film Circulation on the International Film Festival Network and the Impact on Global Film Culture" (2017-2020). She has published 
widely on film festivals, queer film culture, gender in media studies, and media industries. Deb Verhoeven is Canada 150 Research Chair in Gender and Cultural Informatics. Prior to taking up this position she was Associate Dean of Engagement and Innovation at the University of Technology Sydney (UTS). She is a longstanding activist and impact-focused researcher working primarily on the Australian screen industries. Her findings are published widely across trade journals, news outlets, policy reports, academic papers, and monographs.

2 Jodi Kantor and Megan Twohey, "Harvey Weinstein Paid Off Sexual Harassment Accusers for Decades," The New York Times, October 5, 2017, https://www.nytimes. com/2017/10/05/us/harvey-weinstein-harassment-allegations.html (accessed March 8, 2019).

${ }^{3}$ A special issue edited by Shelley Cobb and Tanya Horeck, "Post Weinstein: Gendered Power and Harassment in the Media Industries," Feminist Media Studies 18 (3, 2018): 489-91, has addressed this with articles on the Scandinavian and South Korean contexts: See Inge Sørensen, "What Sexual Harassment in Zentropa Tells Us about Cultural Policy Post-Weinstein," Feminist Media Studies 18 (3, 2018): 502-5, and Jinsook Kim, "After the Disclosures: A Year of \#sexual_violence_in_the_film_ industry in South Korea," Feminist Media Studies 18 (3, 2018): 505-8.

${ }^{4}$ For comparative statistics in the European film industry, see Holly Aylett, "Where Are All the Women Directors? Report on Gender Equality for Directors in the European Film Industry," EWA Women Directors in Film-Comparative Report, European Women's Audiovisual Network (EWA), 2016; for a discussion of the measures taken by Denmark, see Eva Nordrup Redvall and Inge E. Sørensen, "Hard Facts, Soft Measures: Gender, Quality and Inequality Debates in Danish Film and Television in the 2010s," Journal of Scandinavian Cinema 8 (3, 2018): 233-49, and for the Austrian take, see Francine H. Raveney, Birgit Moldaschl and Anna Koblitz, "Gender Inequality for Directors in the European Film Industry: Focus on Austria," in Handbook of State Aid for Film: Finance, Industries and Regulation, ed. Paul C. Murschetz, Roland Teichmann and Matthias Karmasin (Cham: Springer International, 2018), 509-30.

\section{ORCID iD}

Skadi Loist iD https:/ /orcid.org/0000-0002-8299-4103

Deb Verhoeven (D) https://orcid.org/0000-0003-3680-3561

\section{Bibliography}

Aylett, Holly. "Where Are All the Women Directors? Report on Gender Equality for Directors in the European Film Industry." EWA Women Directors in Film-Comparative Report, European Women's Audiovisual Network (EWA), 2016. 
Cobb, Shelley, and Tanya Horeck. "Post Weinstein: Gendered Power and Harassment in the Media Industries." Feminist Media Studies 18, no. 3 (2018): 489-91. doi:10.1080/14680 777.2018.1456155.

Kantor, Jodi, and Megan Twohey. "Harvey Weinstein Paid Off Sexual Harassment Accusers for Decades." The New York Times, October 5, 2017. Accessed March 8, 2019. https:// www.nytimes.com/2017/10/05/us /harvey-weinstein-harassment-allegations. html.

Kim, Jinsook. "After the Disclosures: A Year of \#sexual_violence_in_the_film_industry in South Korea." Feminist Media Studies 18, no. 3 (2018): 505-8. doi:10.1080/14680777.20 18.1456168.

Raveney, Francine H., Birgit Moldaschl, and Anna Koblitz. "Gender Inequality for Directors in the European Film Industry: Focus on Austria." In Handbook of State Aid for Film: Finance, Industries and Regulation, edited by Paul C. Murschetz, Roland Teichmann and Matthias Karmasin, 509-30. Cham: Springer International, 2018.

Redvall, Eva N., and Inge E. Sørensen. "Hard Facts, Soft Measures: Gender, Quality and Inequality Debates in Danish Film and Television in the 2010s." Journal of Scandinavian Cinema 8, no. 3 (2018): 233-49. doi:10.1386/jsca.8.3.233_1.

Sørensen, Inge. "What Sexual Harassment in Zentropa Tells Us about Cultural Policy PostWeinstein." Feminist Media Studies 18, no. 3 (2018): 502-5. doi:10.1080/14680777.2018 .1456165 . 
